\title{
Removal of Drugs by Cuttlefish Bone Powder: Equilibrium, Kinetics and Thermodynamic Study
}

\section{Hassen Khazri' ${ }^{1,2 *}$, Ibtissem Ghorbel-Abid ${ }^{1,2}$}

${ }^{1}$ and Malika Trabelsi-Ayadi ${ }^{2}$

${ }^{1}$ Laboratoire Matériaux, Traitement et Analyse, Institut, National de Recherche et d'Analyse Physico-chimique, BiotechPole Sidi-Thabet, 2020 Ariana, Tunisia ${ }^{2}$ Laboratory of Application Chemistry to the Resources and Natural Substances and the Environment (LACReSNE), Faculty of Science of Bizerte, 7021 Zarzouna, Bizerte, Tunisia

\begin{abstract}
This study aimed to describe the adsorption of three pharmaceuticals which represents a source of environment contamination. The adsorption of three drugs: ibuprofen (IBU), naproxen (NAP) and carbamazepine (CBZ) from river water onto cuttlefish bone powder (CFPB) as adsorbent material were carried of various parameters such as contact time, the effect of $\mathrm{pH}$, the varying of the concentration and the temperature.

Adsorption kinetic data were modeled using the Lagergren first order and the pseudo-second order kinetic equations. The kinetic results of adsorption are described better by using the pseudo-second order model. Freundlich and DR equations provided better compatibility than Langmuir equation. The thermodynamic parameters obtained indicate that the adsorption of pharmaceuticals on the cuttlefish bone powder is a spontaneous and endothermic process.
\end{abstract}

Keywords: Drugs; Cuttlefish bone powder; Adsorption; Kinetics; Isotherms; Thermodynamics

\section{Introduction}

In recent years, the occurrence, and adverse effects of pharmaceutical residues in aquatic organisms have become an issue for the whole world $[1,2]$. The presence of these products in wastewater and surface water has been proven for many years by several studies [36]. They are detected at low concentrations, ranging from $1 \mu \mathrm{g}$ to ng. $\mathrm{L}^{-}$ ${ }^{1}$ but the continuous release and fugitive emissions of these residues make micro-persistent contaminants [7]. Only a few studies have been carried out using (CFBP) as adsorbent Ben Nasr et al. studied the efficiency of cuttlefish bone in removing fluoride from water. The removal efficacy of the reactive blue dye using cuttlefish bone [8]. The innovation of this research was to study the effectiveness of using bone meal cuttlefish as adsorbent in removing pharmaceuticals doped in an aqueous matrix.

\section{Materials and Methods}

\section{Presentation of materials}

Cuttlefish are generally within a size range from 15 to $25 \mathrm{~cm}$, containing within bone 10 to $20 \mathrm{~cm}$ in size. Cuttlefish bone is a hard, brittle material and structured internally. The adsorbent was prepared in the laboratory. Cuttlefish bone was rinsed with deionized water, boiled for $10 \mathrm{~min}$. To desorb any impurities, dried at $103-105^{\circ} \mathrm{C}$ for 24 $\mathrm{h}$ and allowed to cool in a desiccator. In our study, cuttlefish bone was crushed and pulverized, by standard ASTM sieves (range being 60 to 100 meshes), into $150-250 \mu \mathrm{m}$ particles to get uniform size of (CFPB) and used as an adsorbent in the following experiments.

Cuttlefish bone has been characterized in an earlier study [9], it has a well crystallized form. It is mainly composed of $\mathrm{CaCO}_{3}(86 \%)$, its specific surface area is about $5.6 \mathrm{~m}^{2} \mathrm{~g}^{-1}$ and the experimental pHzpc is about 9.6. When the $\mathrm{pH}$ used in the adsorption process was equal to the fzpc, the surface of the cuttlefish bone powder was neutral.

The surface morphology of the (CFPB) before and after sorption was studied with scanning electron microscope (SEM) with (SEM, JSM.6300) model. To gain further insight into the microstructures, TEM investigations were performed using a Tecnai ultra Twin G2- Philips. Samples for analysis were prepared by air-drying a drop of a sonicated suspension of the dried precipitate in ethanol onto copper grids.
Three pharmaceuticals were selected in this research as target compounds: carbamazepine (an antiepileptic), ibuprofen and naproxen (analgesics), the molecular structure and physicochemical properties of these pharmaceuticals are summarized in Table 1.

Drugs solutions with different concentrations were prepared by diluting the stock solution in ultra-pure water. The naproxen, Ibuprofen and Carbamazepine concentration were determined using the absorbance at $230 \mathrm{~nm}, 220 \mathrm{~nm}$ and 271 respectively of the solutions after getting the UV spectra of the solution with a Spectrophotometer (model of SP-3000 Plus).

The adsorption experiments were performed using a kind of aqueous matrice, namely Medjerda river water who is a source of life for farmers and promoted the development of irrigation farming. The main physicochemical and biological of aqueous matrice are summarized in Table 2.

Adsorption experiments: All the adsorption experiments were carried out at $(298 \pm 0.2 \mathrm{~K})$, by batch adsorption. Stock solution of pharmaceuticals were prepared as $50 \mathrm{mg} . \mathrm{L}^{-1}$ by dissolved in aqueous matrix. Individual batch adsorption experiments were carried out by shaking $25 \mathrm{mg}$ of (CFBP) with $25 \mathrm{~mL}$ of pharmaceuticals solution in a series of reagent flasks at a Constant speed $(250 \mathrm{rpm})$ in a mechanical shaker for $6 \mathrm{~h}$ and centrifuged at $6000 \mathrm{rpm}$, after samples were separated with the aid of a syringe nylon micro filter $(0.22 \mu \mathrm{m})$ and the concentration of each solution was measured by spectrophotometer at the corresponding wavelength and the concentrations were calculated by using calibration curves prepared initially. The $\mathrm{pH}$ of pharmaceuticals solution was adjusted with $(0.1 \mathrm{M}) \mathrm{HCl}$ or $(0.1 \mathrm{M})$ $\mathrm{NaOH}$.

*Corresponding author: Hassen Khazri, Laboratory of Methods and Techniques of Analysis (LMTA), National Institute of Research and Physico-Chemical Analysis (INRAP), Technological Pole 2020, Sidi Thabet, Ariana, Tunisia, Tel: 21641509267; E-mail: khazrihassen12@gmail.com

Received February 09, 2016; Accepted March 25, 2016; Published March 31, 2016

Citation: Khazri H, Ghorbel-Abid I, Kalfat R, Trabelsi-Ayadi M (2016) Removal of Drugs by Cuttlefish Bone Powder: Equilibrium, Kinetics and Thermodynamic Study. J Environ Anal Chem 3: 176. doi:10.41722380-2391.1000176

Copyright: $\odot 2016$ Khazri $\mathrm{H}$, et al. This is an open-access article distributed under the terms of the Creative Commons Attribution License, which permits unrestricted use, distribution, and reproduction in any medium, provided the original author and source are credited. 
Citation: Khazri H, Ghorbel-Abid I, Kalfat R, Trabelsi-Ayadi M (2016) Removal of Drugs by Cuttlefish Bone Powder: Equilibrium, Kinetics and Thermodynamic Study. J Environ Anal Chem 3: 176. doi:10.41722380-2391.1000176

Page 2 of 7

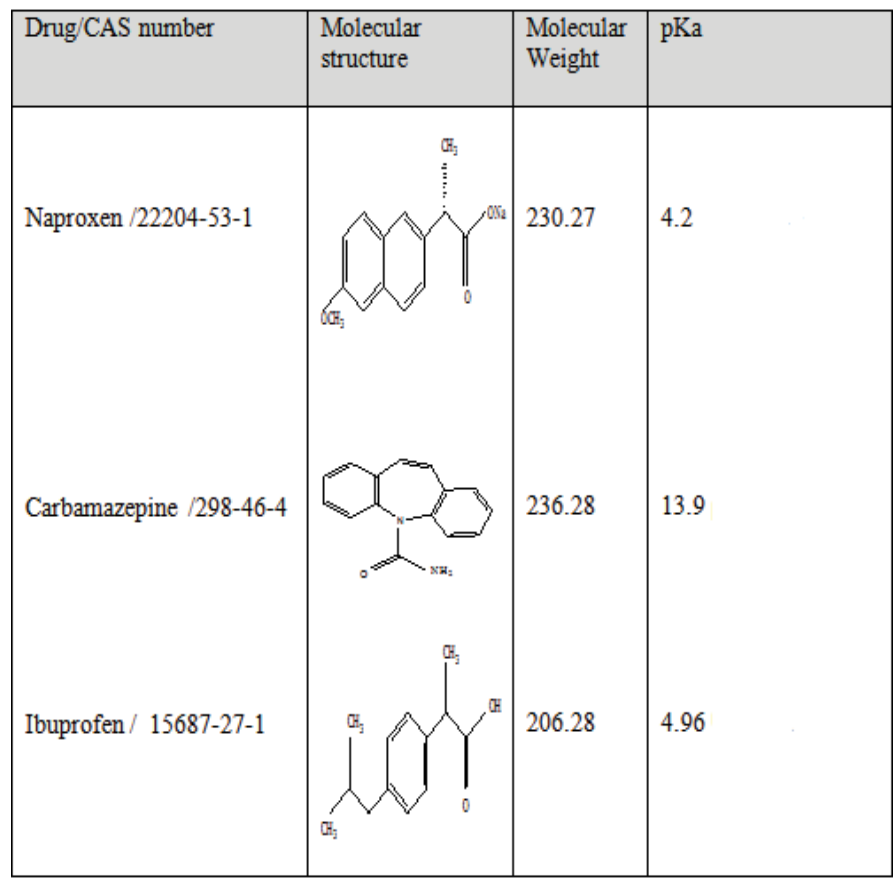

Table 1: Molecular structure and main physicochemical properties of studied pharmaceuticals.

\begin{tabular}{|c|c|}
\hline Parameter & Medjerda river base \\
\hline Conductivity $(\mathrm{S} / \mathrm{cm})$ & 480 \\
\hline Turbidity (NTU) & 142 \\
\hline Total Solids (mg/L) & 506 \\
\hline Ammonium (mg N/L) & 1.7 \\
\hline Nitrate $\left(\mathrm{mg} \mathrm{NO}_{3}^{-}\right)$ & 4.1 \\
\hline Nitrite (mg N/L) & 0.07 \\
\hline Chloride (mg Cl-/L) & 36.2 \\
\hline Oxidability to $\mathrm{KMno}_{4}\left(\mathrm{mg} \mathrm{O}_{2} / \mathrm{L}\right)$ & 44 \\
\hline Bacterial Content (CFU/100ml) & 874 \\
\hline Phosphate (mg P/L) & 0.01 \\
\hline
\end{tabular}

Table 2: Physicochemical and biological characteristics of Medjerda River

\section{Adsorption isotherm}

In order to identify the mechanism of the adsorption process, the adsorption isotherm values were evaluated and analyzed. Different isotherm models are available in the literature. Simple, reliable, and widely used models, such as linear, Langmuir, and Freundlich isotherms, were used in this present study. The chosen isotherm models were applied to establish the relationship between the amount of pharmaceuticals adsorbed by the (CFBP) and its equilibrium concentration in the actual sample. The equilibrium studies were carried out using $25 \mathrm{mg}$ of (CFBP) in $25 \mathrm{~mL}$ of pharmaceuticals aqueous at different concentrations. The sorption capacity of the (CFBP) was evaluated by the amount of pharmaceuticals aqueous adsorbed using the following expression:

$$
\boldsymbol{Q}_{t}=\frac{\left(\boldsymbol{C}_{0}-\boldsymbol{C}_{e}\right) \cdot \boldsymbol{V}}{\boldsymbol{M}}
$$

Where, $\mathrm{Q}$ is the amount of solute retained per mass unit of the adsorbent $\left(\mathrm{mg} \mathrm{g}^{-1}\right), \mathrm{C}_{0}$ and $\mathrm{C}_{\mathrm{e}}$ are the initial and equilibrium concentration of pharmaceuticals in the matrice aqueous (mg.L-1). M is the amount of sorbent $(\mathrm{g})$, and $\mathrm{V}$ is the volume of the solution $(\mathrm{L})$.
The percentage of the pharmaceuticals was evaluated as follows:

$$
\boldsymbol{R}(\%)=\frac{\left(\boldsymbol{C}_{0}-\boldsymbol{C}_{e}\right) \cdot 100}{\boldsymbol{C}_{0}}
$$

The Langmuir model assumes that the adsorbent surface is homogeneous and contains only one type of binding site, so the energy of adsorption is constant, which is presented by the following equation:

$$
\boldsymbol{Q}_{e}=\frac{\boldsymbol{K}_{L} \cdot \boldsymbol{Q}_{e} \cdot \boldsymbol{C}_{e}}{\left(1+\left(\boldsymbol{K}_{L} \cdot \boldsymbol{C}_{e}\right)\right)}
$$

The linear form of Langmuir adsorption isotherm can be expressed as follows:

$$
\frac{\boldsymbol{C}_{\boldsymbol{e}}}{\boldsymbol{Q}_{\boldsymbol{e}}}=\frac{1}{\mathbf{Q}_{0} \cdot \mathbf{K}_{\mathrm{L}}}+\frac{1}{\mathbf{Q}_{0}} \cdot \boldsymbol{C}_{\boldsymbol{e}}
$$

Where $\mathrm{Q}_{0}\left(\mathrm{mg}^{\mathrm{g}} \mathrm{g}^{-1}\right)$ is the Langmuir constant related to the maximum monolayer adsorption capacity and $\mathrm{K}_{\mathrm{L}}\left(\mathrm{L} \cdot \mathrm{mg}^{-1}\right)$ is the constant related to the free energy or net enthalpy of the adsorption [10]. The Freundlich model can be applied for multilayer adsorption on a heterogeneous adsorbent surface, with sites that have different energies of adsorption. The Freundlich model is given by the following equation [11].

$$
\boldsymbol{Q}_{e}=\boldsymbol{K}_{F} \cdot\left(\boldsymbol{C}_{e}^{\frac{1}{n}}\right)
$$

This expression can be linearized to give the following equation:

$$
\operatorname{Ln} Q_{e}=\operatorname{Ln} K_{F}+\frac{1}{n} \cdot \operatorname{Ln} C_{e}
$$

Where " $\mathrm{K}_{\mathrm{F}}$ " (mg.g $\mathrm{g}^{-1}$ ) and "n" are Freundlich constants related to adsorption capacity and intensity, respectively. Dubinin-Radushkevich (DR) isotherm has been used to describe the sorption of drugs onto (CFBP) and helps in understanding the type of adsorption $[12,13]$. DR equation can be written as Eq. (7).

The DR equation has the following form

$$
\ln q \boldsymbol{e}=\ln q s-\boldsymbol{k} \varepsilon^{2}
$$

where $q_{e}$ is DR monolayer capacity $\left(\mathrm{mg} \mathrm{g}^{-1}\right), k$ is a constant related to adsorption energy; $q_{\mathrm{s}}$ is the amount of drugs adsorbed per unit weight of adsorbent $\left(\mathrm{mg} \mathrm{g}^{-1}\right)$ and $\varepsilon$ is the Polanyi Potential, which can be expressed as:

$$
\boldsymbol{\varepsilon}=\boldsymbol{R} \boldsymbol{T} \ln \left(1+\frac{1}{\boldsymbol{C e}}\right)
$$

Where $C_{\mathrm{e}}$ is the equilibrium concentration of drug in aqueous matrix (mg. $\left.\mathrm{L}^{-1}\right), R$ is the gas constant and $T$ is the temperature (K), the slope of the line makes it possible to calculate the value of $\mathrm{k}$ and the intercept gives the adsorption capacity, $\mathrm{q}_{\mathrm{m}}$.

Adsorption kinetics: Kinetic models are helpful in understanding the mechanism of molecule adsorption and in evaluating the performance of the adsorbents. A number of kinetic models have been developed to describe the kinetics of heavy molecule adsorption. In this present study, the kinetic of pharmaceuticals adsorption on the (CFBP) were determined with different kinetic models such as the first-order and the pseudo-second-order models.

The period of time necessary to reach the equilibrium, previous kinetic experiments were performed. Fixed amounts of adsorbent ( 25 $\mathrm{mg})$ and volumes of adsorptive the aqueous matrix $(25 \mathrm{~mL})$ of initial concentration equal to (50 mg. $\left.\mathrm{L}^{-1}\right)$ were kept in contact under shaking $(250 \mathrm{rpm})$ and at constant temperature $\left(\mathrm{T}=298 \pm 0.2^{\circ} \mathrm{K}\right)$ for different 
Citation: Khazri H, Ghorbel-Abid I, Kalfat R, Trabelsi-Ayadi M (2016) Removal of Drugs by Cuttlefish Bone Powder: Equilibrium, Kinetics and Thermodynamic Study. J Environ Anal Chem 3: 176. doi:10.41722380-2391.1000176

Page 3 of 7

preset time intervals ( 0 min to $360 \mathrm{~min}$ ). Whenever varies in time we take a sample and make it past the centrifuge.

Finally the supernatant was analyzed by spectrometer. The firstorder rate equation of the Lagergren is one of the most widely used kinetic models for the adsorption of a solute from a solution [14]. The model has the following form:

$$
\frac{d Q}{d t}=K\left(Q_{e}-Q_{t}\right)
$$

Where Qe (mg. $\left.\mathrm{g}^{-1}\right)$ is the amount of the metal ions adsorbed on the adsorbent at equilibrium, and $\mathrm{K}_{1}\left(\mathrm{~min}^{-1}\right)$ is the rate constant of the first-order adsorption. After integration and application of boundary conditions $\mathrm{Q}_{\mathrm{t}}=0$ at $\mathrm{t}=0$ and $\mathrm{Q}_{\mathrm{t}}=\mathrm{Q}_{\mathrm{t}}$ at $\mathrm{t}=\mathrm{t}$, the integral form of $\mathrm{Eq}(8)$ becomes the following:

$$
\boldsymbol{L n}\left(\boldsymbol{Q}_{e}-\boldsymbol{Q}_{t}\right)=\ln \boldsymbol{Q}_{e}-\boldsymbol{K}_{1} \cdot \boldsymbol{t}
$$

The second-order kinetic model, on the basis of the adsorption equilibrium capacity, is as follows [13].

$$
\frac{d Q}{d t}=K_{2}\left(Q_{e}-Q_{t}\right)^{2}
$$

Where $\mathrm{K}_{2}\left(\mathrm{~g} \cdot \mathrm{mg}^{-1} \cdot \mathrm{min}^{-1}\right)$ is the rate constant of the second-order equation and $\mathrm{q}\left(\mathrm{mg}^{-1} \mathrm{~g}^{-1}\right)$ is the maximum dye adsorbed. After definite integration through the application of boundary conditions $Q_{t}=0$ at $t=0$ and $\mathrm{Q}_{\mathrm{t}}=\mathrm{Q}_{\mathrm{t}}$ at $\mathrm{t}=\mathrm{t}$, Eq (10) becomes the following:

$$
\frac{\boldsymbol{t}}{\boldsymbol{Q}_{\boldsymbol{t}}}=\frac{1}{2\left(\boldsymbol{Q}_{e}^{2} \cdot \boldsymbol{K}_{2}\right)}+\frac{\boldsymbol{t}}{\boldsymbol{Q}_{e}}
$$

If the second-order kinetic model is applicable, then the plot of $\frac{\boldsymbol{t}}{\boldsymbol{Q}_{e}}$ versus $t$ should give a straight line, and $\mathrm{Q}_{e}$ and $\mathrm{K}_{2}$ could be obtained from the slope and intercept of the straight line, respectively.

Sorption thermodynamics: Thermodynamic parameters, including changes in the free energy $\left(\Delta \mathrm{G}^{\circ}\right)$, enthalpy $\left(\Delta \mathrm{H}^{\circ}\right)$, and entropy $\left(\Delta \mathrm{S}^{\circ}\right)$ associated with the adsorption process, can be determined by using the following equations $[15,16]$.

$$
\begin{aligned}
\Delta \boldsymbol{G}^{\circ} & =-\boldsymbol{R} \operatorname{Tln} K \boldsymbol{c} \\
\Delta \boldsymbol{G}^{\circ} & =\Delta \boldsymbol{H}^{\circ}-\boldsymbol{T} \Delta \boldsymbol{S}^{\circ}
\end{aligned}
$$

The plot of $\mathrm{LnK}_{\mathrm{c}}$, as a function of $\frac{1}{T}$, yields a straight line, from which $\Delta \mathrm{H}^{\circ}$ and $\Delta \mathrm{S}^{\circ}$ can be calculated from the slope and intercept, respectively.

\section{Results and Discussion}

\section{Characteristics of the cuttlefish bone powder}

The chemical composition in weight percentage for the raw material denoted as (CFPB) is given in Table 3 . The chemical composition in weight percentage for the raw material of (CFPB) is given in Table 3.

The textural structural examination of (CFPB) and (CFPB) after the adsorption can be observed from the TEM photographs which are shown in Figure 1.

In Figure 1a, (CFPB) had a very porous structure which could easily absorb pharmaceuticals. Also, the surface change in the TEM photograph of the (CFPB) after adsorption of pharmaceuticals indicates the structural changes in the sorbent which is depicted in Figure 1b.

The point of zero charge (pZC) of the (CFPB) used in this study is presented in Figure 2.

\section{Effect of contact time}

The CFPB have a point of zero charge ( $\mathrm{pZC}$ ) at a $\mathrm{pH}=9.8$, When the $\mathrm{pH}$ used in the adsorption process was equal to 9.8 , the surface of the cuttlefish bone powder was neutral.

Figure 3 shows pharmaceuticals removal at different contact times using (CFPB) as an adsorbent. Pharmaceuticals removal increased rather rapidly with the increase of contact time, but then gradually

\begin{tabular}{|c|c|c|c|c|} 
& $\mathrm{CaCO}_{3}$ & $\mathrm{Na}_{2} \mathbf{O}$ & $\mathbf{P}_{2} \mathbf{O}_{5}$ & $\mathrm{FeO}_{3}$ \\
\hline Wt (\%)CFPB & 86 & 8.275 & 0.218 & 1.128 \\
\hline
\end{tabular}

Table 3: Chemical composition of cuttlefish bone powder.
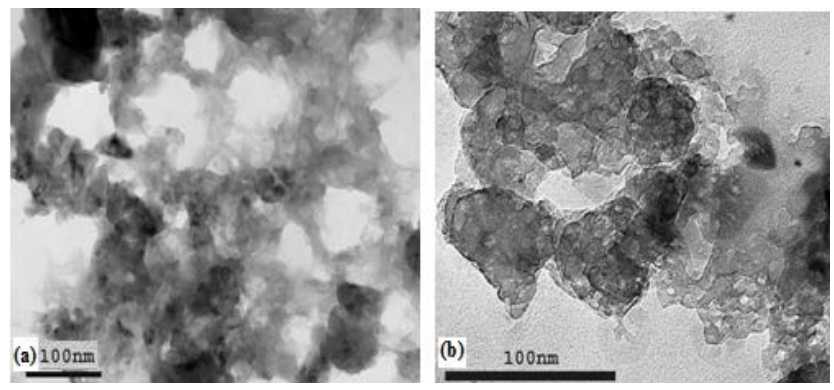

Figure 1: TEM images of (CFBP) and (CFBP) after adsorption of pharmaceuticals.

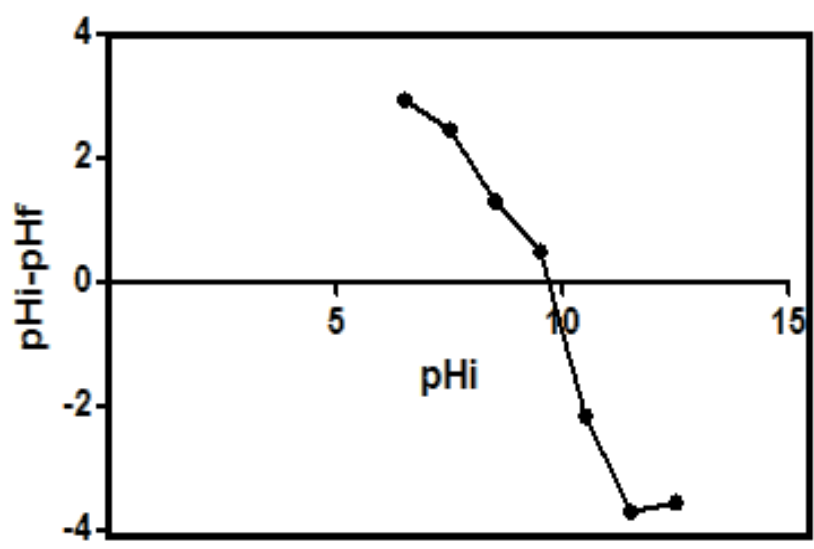

Figure 2: Zeta potential of (CFBP)

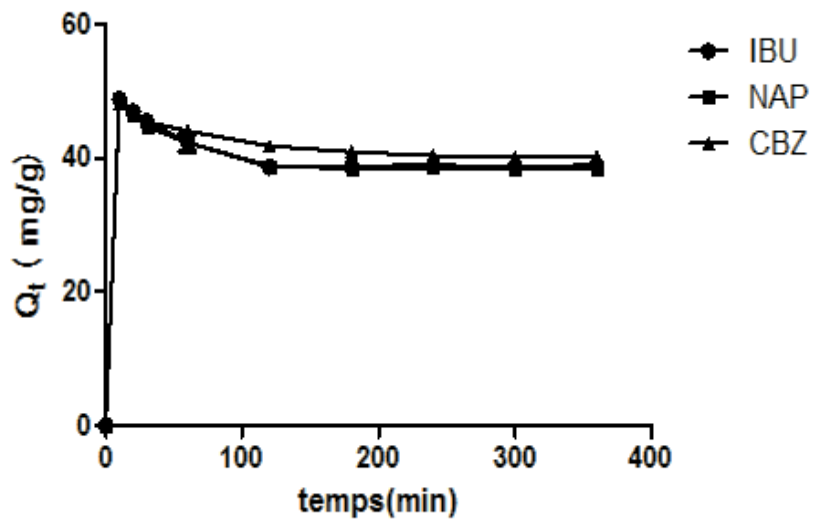

Figure 3: Effect of contact time on the adsorption of pharmaceuticals onto the (CFBP) $\left(\mathrm{T}=298.0 \pm 0.2^{\circ} \mathrm{K}, \mathrm{pH}=7.5\right)$. 
approached a more or less constant value denoting attainment of equilibrium. The fast kinetics of adsorption during the first minutes of the reaction, can be interpreted by the fact that at the beginning of adsorption, the pores available on surface of the adsorbent material is important than that remaining after a certain time $[17,18]$. In addition a specific chemical interaction, diffusion and other driving forces. Besides, the sorption rate decreased due to the non-availability of sorption sites result of the migration of pharmaceuticals to the pore surfaces. The maximum adsorption of pharmaceuticals onto (CFPB) was observed at $180 \mathrm{~min}$ for CBZ, $120 \mathrm{~min}$ for NAP and IBU.

\section{Modeling of adsorption isotherm}

According to the results shown in Figures 4 and 5, we note that the pseudo second order model is the most reliable way to determine the order of adsorption kinetics for all pharmaceuticals by CFPB, which is reflected by the extremely high determination coefficients $\left(\mathrm{R}_{2}>0.999\right)$.

Well and after values $Q_{e}$ shown in Table 4, we note that the values calculated by the pseudo second order model are close to that determined experimentally; as a result the adsorption kinetics of pharmaceuticals used by (CFPB) are a pseudo second order.

\section{Adsorption Isotherms}

Figure 6 shows the influence of the concentration in the ability of pharmaceuticals amount adsorbed which increases with the rise of equilibrium concentration. As can be seen, the adsorption efficacy ranking is as follows: carbamazepine $\left(Q_{e}=43.9 \mathrm{mg} \cdot \mathrm{g}^{-1}\right)$, ibuprofen $\left(Q_{e}=37.6 \mathrm{mg} \cdot \mathrm{g}^{-1}\right)$ and naproxen $\left(\mathrm{Q}_{\mathrm{e}}=36.5 \mathrm{mg} \cdot \mathrm{g}^{-1}\right)$. This could be due to the fact that, at $\mathrm{pH} \mathrm{7,} \mathrm{carbamazepine} \mathrm{is} \mathrm{in} \mathrm{its} \mathrm{neutral} \mathrm{form.} \mathrm{On} \mathrm{the}$ contrary, naproxen and ibuprofen are both deprotonated and thus negatively charged, as they are acidic drugs, as the surface(CFPB) of the adsorbent close to its neutral form, it is reasonable thinking that carbamazepine will be absorbed in a more favorable manner than the remaining molecules.

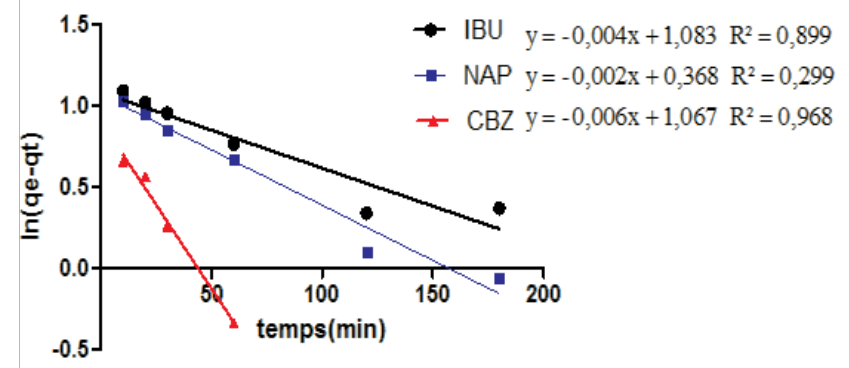

Figure 4: First order model equation of pharmaceuticals adsorption.

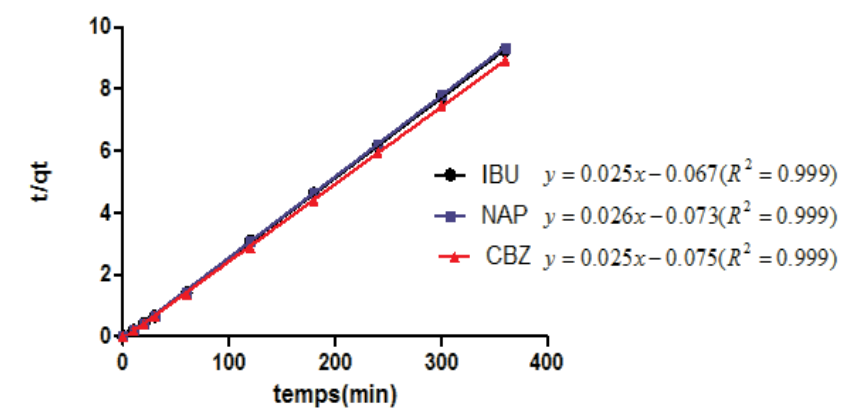

Figure 5: Pseudo second-order model equation for pharmaceuticals adsorption.

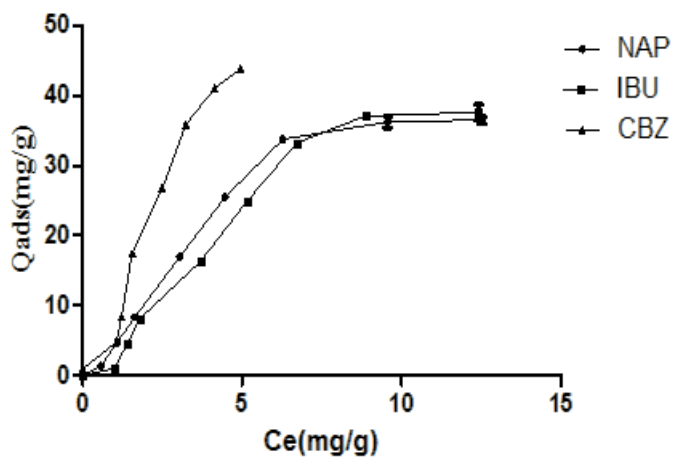

Figure 6: Adsorption isotherm on pharmaceuticals onto cuttlefish bone powder $\left(\mathrm{pH}=8, \mathrm{~T}=298.0 \pm 0.2^{\circ} \mathrm{K}\right)$.

\begin{tabular}{|c|c|c|c|c|c|c|c|c|}
\hline \multirow[b]{2}{*}{ PPs } & \multirow[b]{2}{*}{ Sorbent } & \multirow[b]{2}{*}{$\begin{array}{c}Q_{\exp } \\
(\mathbf{m g} . \\
\left.\mathbf{g}^{-1}\right)\end{array}$} & \multirow[b]{2}{*}{$\begin{array}{c}\mathbf{Q}_{\text {cal }} \\
(\mathbf{m g} . \\
\left.\mathbf{g}^{-1}\right)\end{array}$} & \multirow[b]{2}{*}{$\begin{array}{c}\mathrm{K}_{1} \\
\left(\mathrm{~min}^{-1}\right)\end{array}$} & \multirow[b]{2}{*}{$\mathbf{R}^{2}$} & \multicolumn{3}{|c|}{$\begin{array}{l}\text { Pseudo-second order rate } \\
\text { parameters }\end{array}$} \\
\hline & & & & & & $\begin{array}{c}Q_{\text {cal }} \\
\left(\mathrm{mg} \cdot \mathbf{g}^{-1}\right)\end{array}$ & $\begin{array}{c}\mathrm{K}_{2} \\
\underset{\left.\mathrm{min}^{-1}\right)}{\left(\mathrm{g} \cdot \mathrm{mg}^{-1}\right.} \text {. }\end{array}$ & $\mathbf{R}^{2}$ \\
\hline IBU & & 36.85 & 1.004 & 1.083 & 0.899 & 40 & 0.004 & 0.999 \\
\hline NAP & CFPB & 36.64 & 1.002 & 0.368 & 0.299 & 38.43 & 0.0046 & 0.999 \\
\hline CBZ & & 32 & 1.006 & 1.067 & 0.968 & 40 & 0.0041 & 0.999 \\
\hline
\end{tabular}

Table 4: Kinetic parameters for the adsorption of pharmaceuticals onto (CFBP).

The shape of the isotherm pharmaceuticals at $\mathrm{pH} 7$ is S-type according to the classification of Giles. Who indicates a growth of the adsorption with the concentration of the adsorbate. This is due to the interactions between the molecules which are attracted to Vander Waals forces.

\section{Sorbent isotherms}

The linear, Langmuir and Freundlich equations are commonly used in describing the adsorption equilibrium of wastewater treatment application.

Figures 7 and 8 show the Freundlich and Langmuir equation obtained by the adsorption of pharmaceuticals onto (CFPB).

Figure 9 shown the $\operatorname{lnq}_{e}$ against $\varepsilon^{2}$; the slopes of the line makes it possible to calculate the value of $k$ and the intercept gives the adsorption capacity, $\mathrm{q}_{\mathrm{m}}$.

The constant $\mathrm{k}$ is used to calculate the mean free energy $\mathrm{E}\left(\mathrm{kJ} \mathrm{mol}^{-1}\right)$ defined as the free energy change when 1 mole of ion is transferred to the surface of the solid from infinity in solution $[19,20]$. The equation can be given as follows:

$$
E=2 k^{\wedge(-1 / 2)}
$$

We note that the linearization of adsorption isotherms of pharmaceuticals (CFPB) is satisfactory with good coefficients correlation. We can say that the Freundlich model is a good adequate for the description of the isotherms adsorption. However, from Figure 7, we deduce that the Langmuir model is not suitable for modeling the adsorption isotherms of pharmaceuticals cuttlefish bone powder throughout the concentration range. For drugs sorption onto CFPB, the mean free energy values obtained in this study are 0.973 (Table 5) of ibuprofen, 0.613 (Table 5) of naproxen and 0.648 (Table 5) $\mathrm{kJ} \mathrm{mol}^{-1}$ of carbamazepine at $298^{\circ} \mathrm{K}$. This indicates the adsorption process is of a physical nature. 


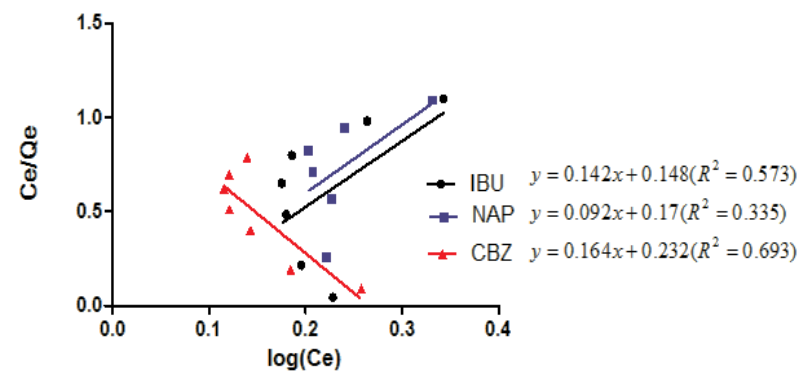

Figure 7: Langmuir model for the adsorption of pharmaceuticals onto (CFBP).

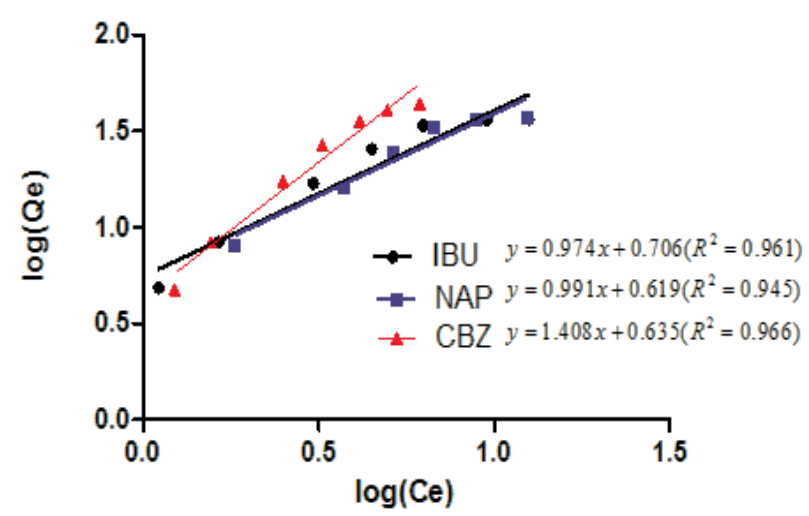

Figure 8: Freundlich model for the adsorption of pharmaceuticals onto (CFBP).

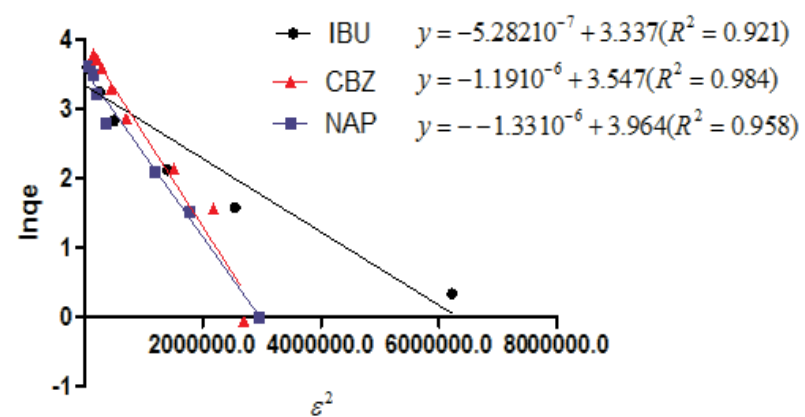

Figure 9: Dubinin-Radushkevich model for the adsorption of pharmaceuticals onto (CFBP).

\section{Effect of $\mathbf{p H}$}

Figure 10 shows the effect of $\mathrm{pH}$ on the removal of pharmaceuticals, into the cuttlefish bone powder at different $\mathrm{pH}$ values. Generally, the adsorption of pharmaceuticals depends strongly on the $\mathrm{pH}$ of the solution [21].

From the figure, it may be concluded that the retention of pharmaceuticals is remarkably influenced by the $\mathrm{pH}$. This parameter has a very important role in the adsorption process and in particular on the adsorption capacity.

In fact, the adsorption efficiency of naproxen and ibuprofen decreases when $\mathrm{pH}$ was increased from 4 to 11 . For carbamazepine, the adsorption efficiency is as high as $81 \%$ in the tested $\mathrm{pH}$ range. The $\mathrm{pKa}$ of naproxen and ibuprofen are 4.2 and 4.96 , respectively, when the $\mathrm{pH}$ is above the $\mathrm{pKa}$, acidic pharmaceuticals have negative charge while surface of adsorbent becomes more negatively charged, leading to an electrostatic repulsion between them.
In addition, Lower $\mathrm{pH}$ effectively provides more $\mathrm{Ca}^{2+}$ due to dissolution of cuttlefish bone which increases the number of positive sites which electrostatically attract negatively charged acidic molecules\% leading to an increase in the amount of acidic molecules removal from the solution. So, adsorption of acidic pharmaceuticals decrease gradually for basic $\mathrm{pH}$ values, the dissociation degree of the surface groups of the (CFPB) as well as that of the chemicals is high, so the adsorbent and the solutes occur in their negatively charged forms. The adsorption of pharmaceuticals onto cuttlefish bone powder can be leading to an electrostatic repulsion between them. This implies that the adsorption decrease. In the case of carbamazepine, it's a neutral compound in the $\mathrm{pH}$ tested range; its binding onto cuttlefish bone powder is solely attributable to a non-electrostatic interaction involving the hydrogen bonding probably through the oxygen groups of estersand Vander Waals interactions [22].

\section{Effect of Temperature}

Figure 11 depicts the adsorption isotherms of pharmaceuticals at different temperatures. The adsorption isotherms shown in Figure 11 indicate clearly that the increase of the temperature affects negatively at the adsorption process. Besides, as temperature raises the adsorption capacity decreases markedly. We noticed that the increase of temperature from 298 to $333 \mathrm{~K}$ induces a decrease of the adsorption capacity. The rise of temperature ensures the destabilization of the physical forces involved, so we concluded that there is an optimum value of temperature in order to promote the adsorption of pharmaceuticals.

In general, the adsorption is always accompanied by a thermal $[23,24]$ which may be either exothermic $\left(\Delta \mathrm{H}^{\circ}<0\right)$ or endothermic $\left(\Delta \mathrm{H}^{\circ}>0\right)$. Measuring the heat of adsorption $\Delta \mathrm{H}^{\circ}$ is the main criterion that differentiates the chemisorption of physisorption.

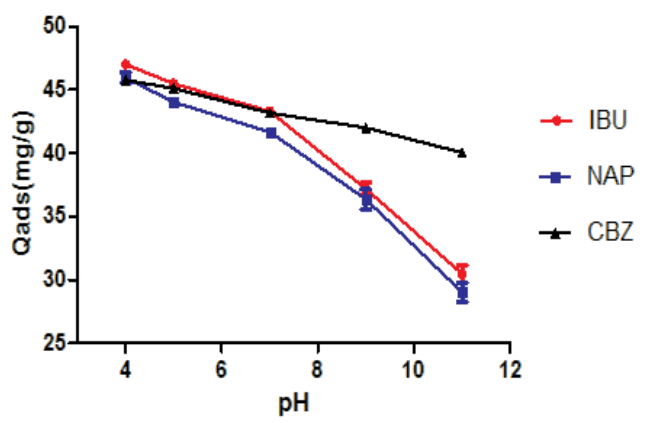

Figure 10: Effect of $\mathrm{pH}$ on the removal of pharmaceuticals onto cuttlefish bone powder $\left(\mathrm{C}_{\mathrm{i}}=50 \mathrm{mgL}^{-1}, \mathrm{~T}=298.0 \pm 0.2{ }^{\circ} \mathrm{K}\right)$.

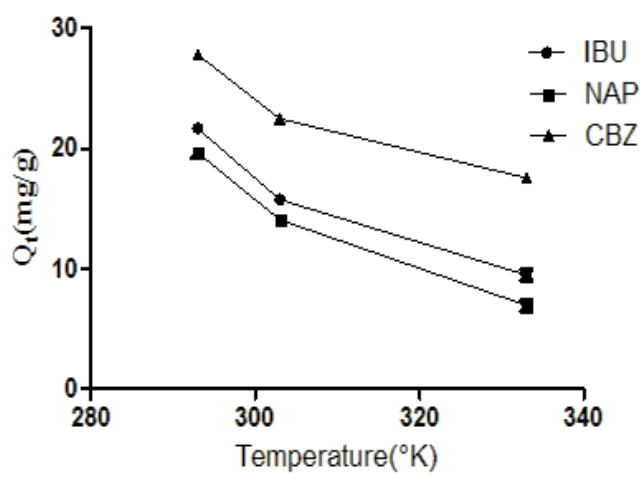

Figure 11: Effect of temperature on the adsorption of pharmaceuticals onto cuttlefish bone powder $\left(\mathrm{C}_{\mathrm{i}}=50 \mathrm{mgL}^{-1}, \mathrm{pH}=8\right)$. 
Citation: Khazri H, Ghorbel-Abid I, Kalfat R, Trabelsi-Ayadi M (2016) Removal of Drugs by Cuttlefish Bone Powder: Equilibrium, Kinetics and Thermodynamic Study. J Environ Anal Chem 3: 176. doi:10.41722380-2391.1000176

Page 6 of 7

The heat of adsorption $\Delta \mathrm{H}^{\circ}$ is given by the Gibbs-Helmholtz relationship [25,26].

$$
\begin{aligned}
& \Delta G^{\circ}=-R T \ln K c \\
& \Delta G^{\circ}=\Delta H^{\circ}-T \Delta S^{\circ} \\
& L n K_{c}=\frac{\Delta S^{\circ}}{R}-\frac{\Delta H^{\circ}}{R \cdot T} \\
& \text { With: } K_{c}=\frac{C_{e}}{M .\left(C_{0}-C_{e}\right)} . V
\end{aligned}
$$

Where, $\mathrm{K}=$ Equilibrium constant; $\Delta \mathrm{G}^{\circ}=\mathrm{Gibbs}$ free energy $(\mathrm{KJ}$. $\left.\mathrm{mol}^{-1}\right) ; \quad \Delta \mathrm{H}^{\circ}=$ Enthalpy $\quad\left(\mathrm{KJ} \cdot \mathrm{mol}^{-1}\right) ; \quad \Delta \mathrm{S}^{\circ}=$ Entropy $\quad\left(\mathrm{KJ} \cdot \mathrm{mol}^{-1} \cdot \mathrm{K}^{-1}\right) ;$ $\mathrm{T}=$ absolute temperature $(\mathrm{K}) ; \mathrm{C}_{\mathrm{o}}=$ initial concentration of the adsorbate; $\mathrm{C}_{\mathrm{e}}=$ equilibrium concentration of the adsorbate; $\mathrm{V}=$ volume of solution; $\mathrm{m}=$ mass of the sorbent; and $\mathrm{R}=$ gas constant $\left(8.314 \mathrm{~J} \cdot \mathrm{mol}^{-1} \cdot \mathrm{K}^{-1}\right)$.

The heat of adsorption $\Delta \mathrm{H}^{\circ}$ and the entropy $\Delta \mathrm{S}^{\circ}$ adsorbate on (CFPB) was determined graphically by plotting LnKc in function of the inverse of the temperature in Kelvin of the medium as shown in the Figure 12.

The positive value of $\Delta \mathrm{H}^{\circ}$ (Table 6) confirms that the adsorption of pharmaceuticals on the cuttlefish bone powder is an endothermic process. Also, the low values of this heat $\left(<40 \mathrm{KJ}^{\mathrm{mol}}{ }^{-1}\right)$ indicate that this is a physical adsorption. The positive value of $\Delta S^{\circ}$ (Table 6) corresponds to an increase in randomness at the solid solution interface. Also, some structural changes may have taken place as a result of interaction of molecules with active groups on CFPB surface [27]. The negative values of $\Delta \mathrm{G}^{\circ}$ (Table 6) at different temperatures for all samples indicate the spontaneous nature of the sorption process of drugs reagent on CFPB.

\section{Acknowledgements}

Thanks for the National institute of Research and Physico-chemical Analysis (INRAP) for support of the analysis.

\section{Conclusion}

Elemental analysis showed that cuttlefish bone consist of $86 \%$ of pure calcium carbonate. TEM and SEM studies reveal that cuttlefish bone has a well crystallized, uniform and porous structured. The kinetic data of pharmaceuticals followed the pseudo second-order kinetic model. Langmuir and Freundlich equations were used to describe adsorption of drugs onto (CFPB). The Freundlich equation is in good agreement with the experimental results. The adsorption isotherms pharmaceuticals of cuttlefish bone powder are satisfactorily described by the Freundlich model. The positive values of $\Delta \mathrm{H}^{\circ}$ confirm the endothermic nature of the adsorption. The increasing values of $\Delta \mathrm{G}^{\circ}$ with temperature show the spontaneity in the sorption processes pharmaceuticals reagent on (CFPB). For drugs sorption onto (CFPB),

\begin{tabular}{|c|c|c|c|}
\hline & IBU & NAP & CBZ \\
\hline \multicolumn{4}{|c|}{ Langmuir Parameters } \\
\hline$Q_{e}(m g . g-1)$ & 7.042 & 10.86 & 6.09 \\
\hline $\mathrm{K}_{\mathrm{L}}\left(\mathrm{mg} \cdot \mathrm{L}^{-1}\right)$ & 0.959 & 0.540 & 0.70 \\
\hline $\mathbf{R}^{2}$ & 0.573 & 0.573 & 0.693 \\
\hline \multicolumn{4}{|c|}{ Freundlich parameters } \\
\hline$K_{f}(m g \cdot g-1)$ & 2.025 & 1.857 & 1.887 \\
\hline$n_{f}$ & 1.04 & 1 & 0.710 \\
\hline $\mathbf{R}^{2}$ & 0.989 & 0.972 & 0.987 \\
\hline \multicolumn{4}{|c|}{ Dubinin-Radushkevich parameters } \\
\hline$Q_{e}(m g \cdot g-1)$ & 28.13 & 52.66 & 34.709 \\
\hline $\mathrm{K}(\mathrm{mol} 2 \mathrm{~J}-2)$ & $5.28210^{-7}$ & $1.3310^{-6}$ & $1.19^{-6}$ \\
\hline $\mathrm{E}(\mathrm{kJmol}-1)$ & 0.973 & 0.613 & 0.648 \\
\hline $\mathbf{R}^{2}$ & 0.921 & 0.958 & 0.984 \\
\hline
\end{tabular}

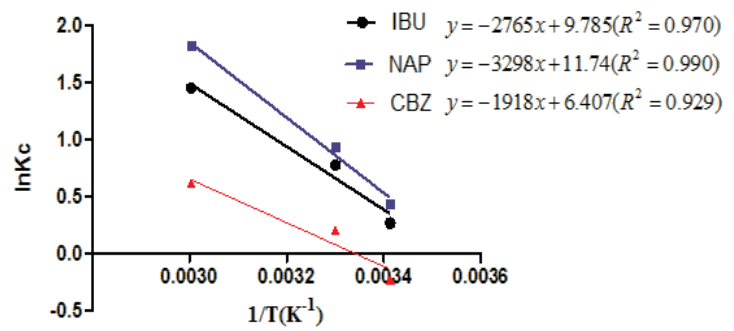

Figure 12: Determination of the enthalpies and entropies of adsorption of pharmaceuticals onto cuttlefish bone powder.

\begin{tabular}{|c|c|c|c|c|}
\hline $\mathbf{T}(\mathbf{K})$ & $\mathrm{K}_{\mathrm{c}}$ & $\Delta H^{\circ}\left(k J . m^{-1}\right)$ & $\underset{\left.\mathbf{K}^{-1}\right)}{\Delta \mathbf{S}^{\circ}\left(\mathbf{k J} . \mathrm{mol}^{-1}\right.}$ & $\Delta \mathrm{G}^{\circ}\left(\mathrm{kJ} \cdot \mathrm{mol}^{-1}\right)$ \\
\hline 293 & 1,30446927 & \multirow[t]{3}{*}{22.889} & \multirow[t]{3}{*}{0.081} & $-647,480248$ \\
\hline 313 & 2,17155214 & & & $-1953,44897$ \\
\hline 333 & 4,26735834 & & & $-4017,16956$ \\
\hline 293 & 1,554447662 & \multirow[t]{3}{*}{27.41} & \multirow[t]{3}{*}{0.097} & $-1058,89377$ \\
\hline 313 & 2,55080831 & & & $-2358,9505$ \\
\hline 333 & 6,17619603 & & & $-5040,7279$ \\
\hline 293 & 0,79587831 & \multirow[t]{3}{*}{0.053} & \multirow[t]{3}{*}{0.053} & 556,16113 \\
\hline 313 & 1,22465354 & & & $-510,524223$ \\
\hline 333 & 1,84780579 & & & $-1699,89395$ \\
\hline
\end{tabular}

Table 5: Isotherm parameters obtained by fitting equilibrium data with the Langmuir, Freundlich and Dubinin-Radushkevich isotherms for the adsorption of pharmaceuticals on (CFBP).

Table 6: Experimental results of thermodynamics of adsorption of pharmaceuticals.

the mean free energy values obtained in this study $\left(\mathrm{E}<8 \mathrm{~kJ} \mathrm{~mol}{ }^{-1}\right)$, the adsorption process is of a physical nature. Finally, cuttlefish shows a remarkable adsorption capacity of drugs in the water of the river which can be a solution to minimize pollution as a result.

\section{References}

1. Jonas M, Kienle C, Magnet A (2013) Treatment of micro pollutants in municipal wastewater: Ozone or powdered activated carbon. Science of the Total Environment, pp: 461-462.

2. Halling-Sorensen $B$, Nors Nielsen S, Lanzky PF, Ingerslev F, Holten Lutzhoft $\mathrm{HC}$, et al. (1998) Occurrence, fate and effects of pharmaceutical substances in the environment--a review. Chemosphere 36: 357-393.

3. Bercu JP, Parke NJ, Fiori JM, Meyerhoff RD (2008) Human health risk assessments for three neuropharmaceutical compounds in surface waters. Regulatory Toxicology and Pharmacology 50: 420-427.

4. Cunningham VL, Binks SP, Olson MJ (2009) Human health risk assessment from the presence of human pharmaceuticals in the aquatic environment Regul Toxicol Pharmacol 53: 39-45.

5. Jones OAH, Voulvoulis N, Lester JN (2004) Potential ecological and human health risks associated with the presence of pharmaceutically active compounds in the aquatic environment. Critical Reviews in Toxicology 34: 335-350.

6. Heberer T (2002) Occurrence, fate, and removal of pharmaceutical residues in the aquatic environment: a review of recent research data. Toxicol Lett 131: 5-17.

7. Daughton CG, Ternes TA (1999) Pharmaceuticals and personal care products in the environment: agents of subtle change? Environ Health Perspect 107 Suppl 6: 907-938.

8. Ghaneian MT, Momtaz M, Dehvari M (2012) An investigation of the efficacy of Cuttlefish bone powder in the removal of Reactive Blue 19 dye from aqueous solutions: equilibrium and Isotherm studies. J Health Res 1: 1-11.

9. Khazri H (2014) Removal of Carbamazepine (CBZ) from aqueous solution using Cuttlefish bones. International Journal of Chemistry and Pharmaceutical 1: 1032-1043. 
Citation: Khazri H, Ghorbel-Abid I, Kalfat R, Trabelsi-Ayadi M (2016) Removal of Drugs by Cuttlefish Bone Powder: Equilibrium, Kinetics and Thermodynamic Study. J Environ Anal Chem 3: 176. doi:10.41722380-2391.1000176

Page 7 of 7

10. Angove MJ, Johnson BB, Wells JD (1997) The Influence of Temperature on the Adsorption of Cadmium (II) and Cobalt (II) on Kaolinite. Colloid Surf. A: Phys Eng Aspects 126: 137-147.

11. Freundlich HMF (1906) Over the adsorption in solution. J Phys Chem 57: 385-470.

12. Donat R, Akdogan A, Erdem E, Cetisli $\mathrm{H}$ (2005) Thermodynamics of $\mathrm{Pb} 2^{+}$ and $\mathrm{Ni}^{+}$adsorption onto natural bentonite from aqueous solutions. J Colloid Interface Sci 286: 43-52.

13. Hosseini M, Mertens SFL, Ghorbani M, Arshadi MR (2003) Asymmetrical Schiff bases as inhibitors of mild steel corrosion in sulphuric acid media. Mater Chem Phys 78: 800-808

14. Lagergren $S$ (1898) About the theory of so-called adsorption of soluble substances. Kungliga Svenska Vetenskapsakademiens Handlingar 24: 1-39

15. Ho YS, McKay G (1998) A two-stage batch sorption optimized design for dye removal to minimize contact time. Process Safety and Environmental Protection 76: 313-318.

16. Moore DM, Reynolds RC (1997) X-ray Diffraction and the Identification and Analysis of Cuttlefish bone powder Minerals, 2nd edn. Oxford University Press.

17. Giles CH, Mac Ewan TH, Nakhwa SN, Smith DJ (1960) Journal of Chemical Society 93: 3973 .

18. Stipp SLS (1999) Toward a conceptual model of the calcite surface: hydration, hydrolysis, and surface potential. Geochimica et Cosmochimica Acta 63: 3121 3131.

19. Polanyi M (1932) Section III- Theories of the adsorption of gases. A general survey and some additional remarks. Introductory paper to section III. Trans Faraday Soc 28: 316-333.
20. Bering BP, Dubinin MM, Serpenski VV (1972) On thermodynamics of adsorption on micropores. J Colloid Interf Sci 38: 185-194.

21. Rivera-Jiménez SM, Méndez-González S, Hernández-Maldonado A (2010) Metal $\left(\mathrm{M}=\mathrm{Co} 2^{+}\right.$, $\mathrm{Ni} 2^{+}$, and $\left.\mathrm{Cu} 2^{+}\right)$grafted mesoporous SBA-15: effect of transition metal incorporation and $\mathrm{pH}$ conditions on the adsorption of Naproxen from water. Micro porous and Mesoporous Materials 132: 470-479.

22. Turku I, Sainio T, Paatero E (2007) Thermodynamics of tetracycline adsorption on silica. Environmental Chemistry Letters 5: 225-228.

23. Rytwo G, Ruiz-Hitzky E (2003) Enthalpies of adsorption of methylene blue and crystal violet to montmorillonite. Journal of thermal analysis and calorimetry 71 : 751-759.

24. Ramesh A, Lee DJ, Wong JW (2005) Thermodynamic parameters for adsorption equilibrium of heavy metals and dyes from wastewater with low-cost adsorbents. J Colloid Interface Sci 291: 588-592.

25. El-Rahman KA, El-Kamash AM, El-Sourougy MR, Abdel-Moniem NM (2006) Thermodynamic modeling for the removal of $\mathrm{Cs}^{+}, \mathrm{Sr}^{+}, \mathrm{Ca}^{+}$and $\mathrm{Mg}^{+}$ions from aqueous waste solutions using zeolite $\mathrm{A}$. Journal of radioanalytical and nuclear chemistry 268: 221-230.

26. Demirbas A, Sari A, Isildak O (2006) Adsorption thermodynamics of stearic acid onto bentonite. J Hazard Mater 135: 226-231.

27. Yadava KP, Tyagi BS, Singh VN (1991) Effect of temperature on the removal of lead (II) by adsorption on china cuttlefish bone powder and wollastonite. Journal of Chemical Technology and Biotechnology 51: 47-60. 